\title{
Temporary Loss of a Metabolic Response to Cold Stress in Infants of Low Birthweight
}

\author{
E. N. HEY and G. KATZ \\ From the Neonatal Research Group, Department of Physiology, The London Hospital Medical College, London
}

Though even very premature infants defend their body temperature by controlling skin blood flow and regulating heat production within hours of birth (Brück and Brück, 1960; Brück, 1961), small babies easily become hypothermic in the first few weeks of life. The tendency to hypothermia is generally attributed to lack of tissue insulation and to the high surface area to body weight ratio. Evidence has now accumulated to suggest that another factor may occasionally operate. We report here observations on 3 infants of low birthweight who were able to increase their heat production normally during the first few days of life when in cool surroundings, but who then lost this ability for a number of days.

\section{Subjects and Methods}

The observations reported here were obtained during studies on a group of 28 infants who weighed between 1 and $2 \mathrm{~kg}$. at birth, and who were examined with the parents' consent at regular intervals during the first 6 weeks of life.

Measurements. Estimates of heat production at various environmental temperatures between 28 and $36{ }^{\circ} \mathrm{C}$. were made by indirect calorimetry using a closed-circuit oxygen consumption apparatus (Hill and Rahimtulla, 1965). The babies were naked except for a thin napkin. Rectal temperature was between 36 and $37.8{ }^{\circ} \mathrm{C}$. The metabolic response to cold stress was normally judged by measuring the $\mathrm{O}_{2}$ consumption for 20 minutes while the infants were in an environment of $29^{\circ} \mathrm{C}$. In a few studies rectal temperature fell nearly a degree during this time; since the temperature of the infant influences mean air temperature in the chamber, a completely steady air temperature was not established in these circumstances, and the change in gas volume in the apparatus overestimated $\mathrm{O}_{2}$ consumption by up to $11 \%$. The results reported here have been corrected for this artefact (Hey, 1969). Heat production was calculated from oxygen consumption on the assumption that the metabolism of 1 litre $\mathrm{O}_{2}$ at s.t.p. (dry) produces $4 \cdot 8 \mathrm{Cal}$. heat.

Received November 20, 1968.
Estimates of mean environmental temperature in the metabolism chamber were obtained from weighted averages of air and wall temperature. Estimates of mean environmental temperature in the single-walled incubators in which the infants were nursed were obtained from a knowledge of room temperature and incubator air temperature using the relations established by Hey and Mount (1967). The calorific value of the milk was calculated using the specific factors established by Southgate and Barrett (1966).

Evaporative water loss and sweat production were measured using the method of Hey and Katz (1969a). Sweating ability was tested when the child was in an environment of $36^{\circ} \mathrm{C}$. or more and rectal temperature was $37.8{ }^{\circ} \mathrm{C}$. Changes in heat loss from the hand were measured by a heat-flow disc (Hatfield and Wilkins, 1950) while the hand was in a water-jacket at constant temperature.

\section{Observations}

Serial observations were obtained on a group of 25 infants who weighed between 1 and $2 \mathrm{~kg}$. at birth, and who remained well throughout the neonatal period. The ability to increase heat production in a cool environment was well maintained, and indeed rose gradually during the first weeks of life (Fig. 1).

A very different pattern of response was detected in 3 further infants who possessed normal physiological responses at birth, but who lost their metabolic response to cold stress for a number of days in the first 3 weeks of life.

Case 1. Male. Birthweight 1515 g. after 30 weeks' gestation. The early neonatal course was clinically uneventful except for a staphylococcal eye infection which responded to chloramphenicol eye drops. The volume of the feeds was increased gradually; the child received a total of $310 \mathrm{Cal}$. in the first 5 days of life. The average incubator air temperature over this period was $32{ }^{\circ} \mathrm{C}$., though it fell accidentally below $30^{\circ} \mathrm{C}$. for a period of over 8 hours on the 4 th day. The infant's resting metabolism in a warm neutral environment and metabolic response to brief cold stress were tested each day for the first 3 days of life and were 


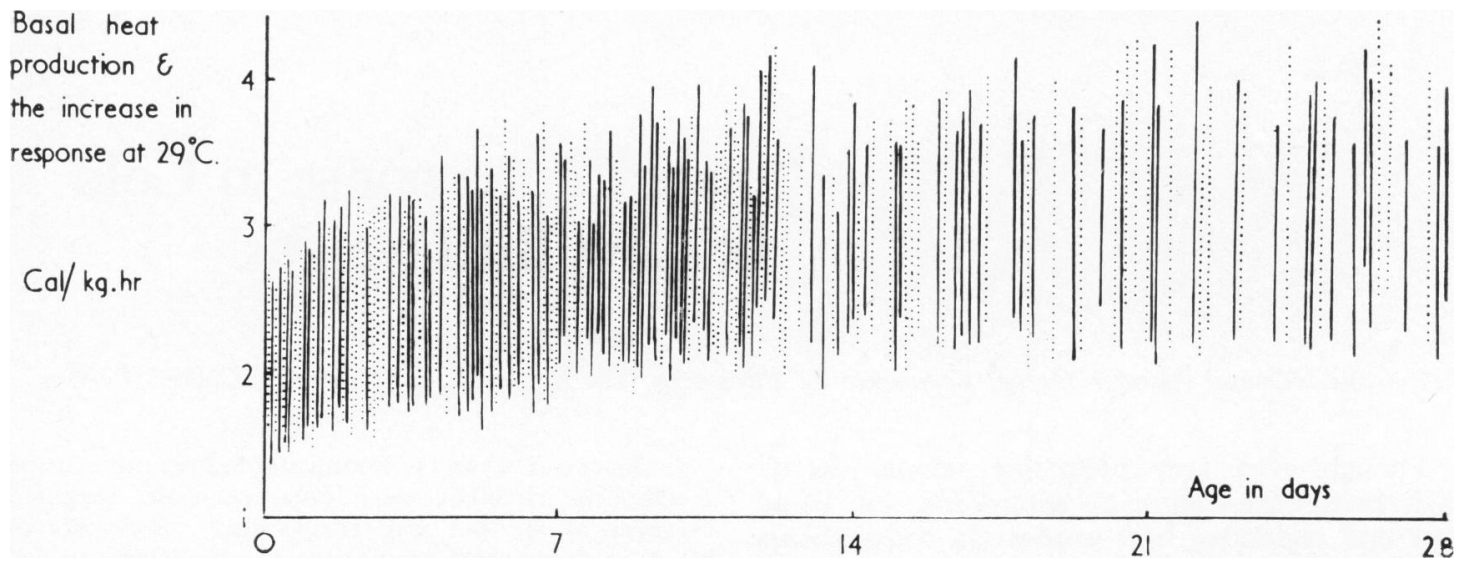

Fig. 1.-Estimates of metabolism in a group of 25 apparently healthy babies weighing between 1 ard $2 \mathrm{~kg}$. at birth, during the first month of life. (Note the suppressed zero on the ordinate.) Lines link the measured basal metabolism in a warm environment with the increase in heat production observed on each occasion that the infants were placed naked in an environment of $29{ }^{\circ} \mathrm{C}$. for a period of 20 minutes. Results obtained on infants weighing over $1.5 \mathrm{~kg}$. at birth are indicated by dotted lines. Space does not allow all the data obtained on infants under 12 days old to be shown. Heat production increases nearly $100 \%$ at $29{ }^{\circ} \mathrm{C}$., and in infants more than 1-2 days old this is normally enough to prevent any rapid fall in body temperature.

normal. Rectal temperature fell to $33{ }^{\circ} \mathrm{C}$. after a drop in incubator temperature on the 6th day; the infant was $13 \%$ below his birthweight. After he had been rewarmed his metabolic response to cold stress was reassessed: it was less than normal. The following day the infant started to pass loose though infrequent stools. Food intake was increased to $150 \mathrm{Cal}$. a day, but unfortunately the incubator temperature continued to fluctuate, rectal temperature remained subnormal, and the child continued to lose weight. The baby's metabolic responses were reassessed on the 8th and 10th days of life: despite considerable activity and restlessness, heat production hardly increased at all when environmental temperature was lowered briefly to $29{ }^{\circ} \mathrm{C}$. (Fig. 2).

Over the next 2 days the infant became dehydrated

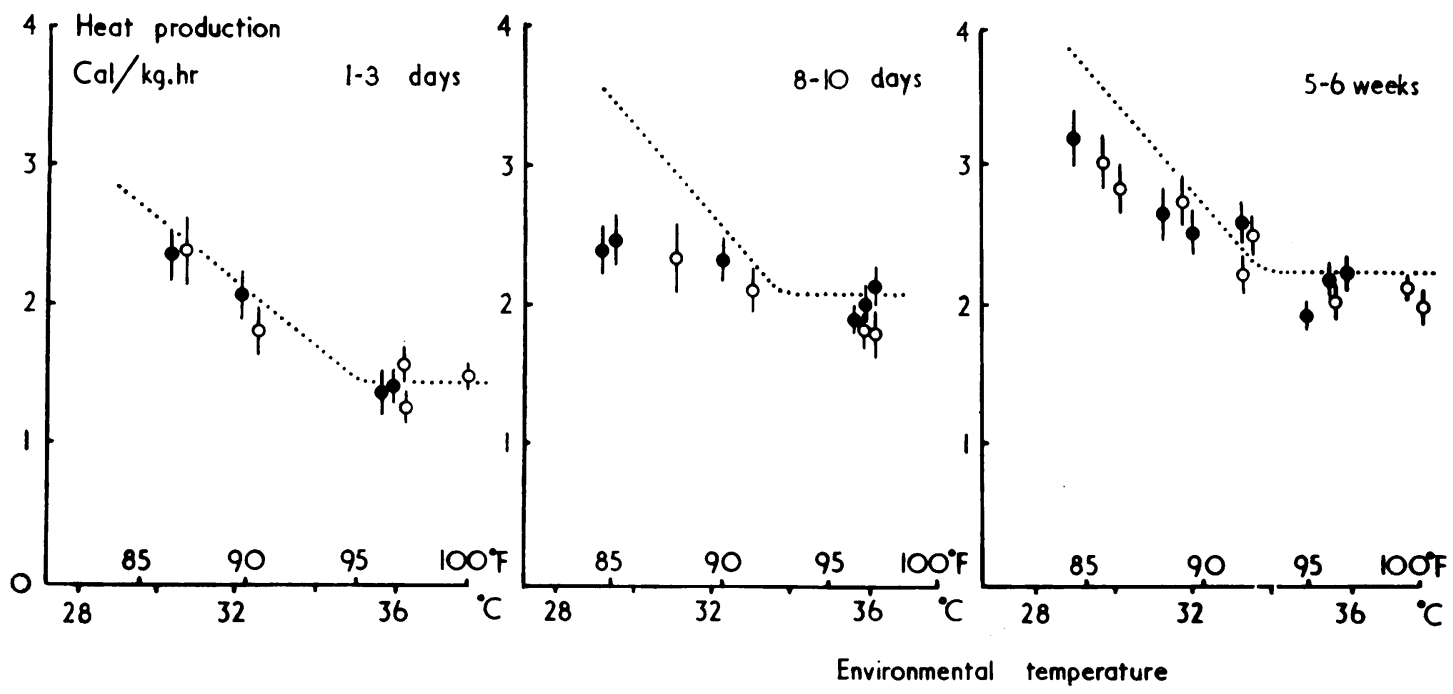

Fig. 2.-The relation between heat production and environmental temperature in Case 1, showing a normal metabolic response to cold in the first 3 days of life, a severely subnormal response when 8 and 10 days old, and a response once more within normal limits when 5 and 6 weeks old. Different symbols have been used to indicate results obtained on different days. The bars indicate the standard errors of the estimates. The dotted lines indicate the average responses found in healthy infants of the same birthweight and age. 

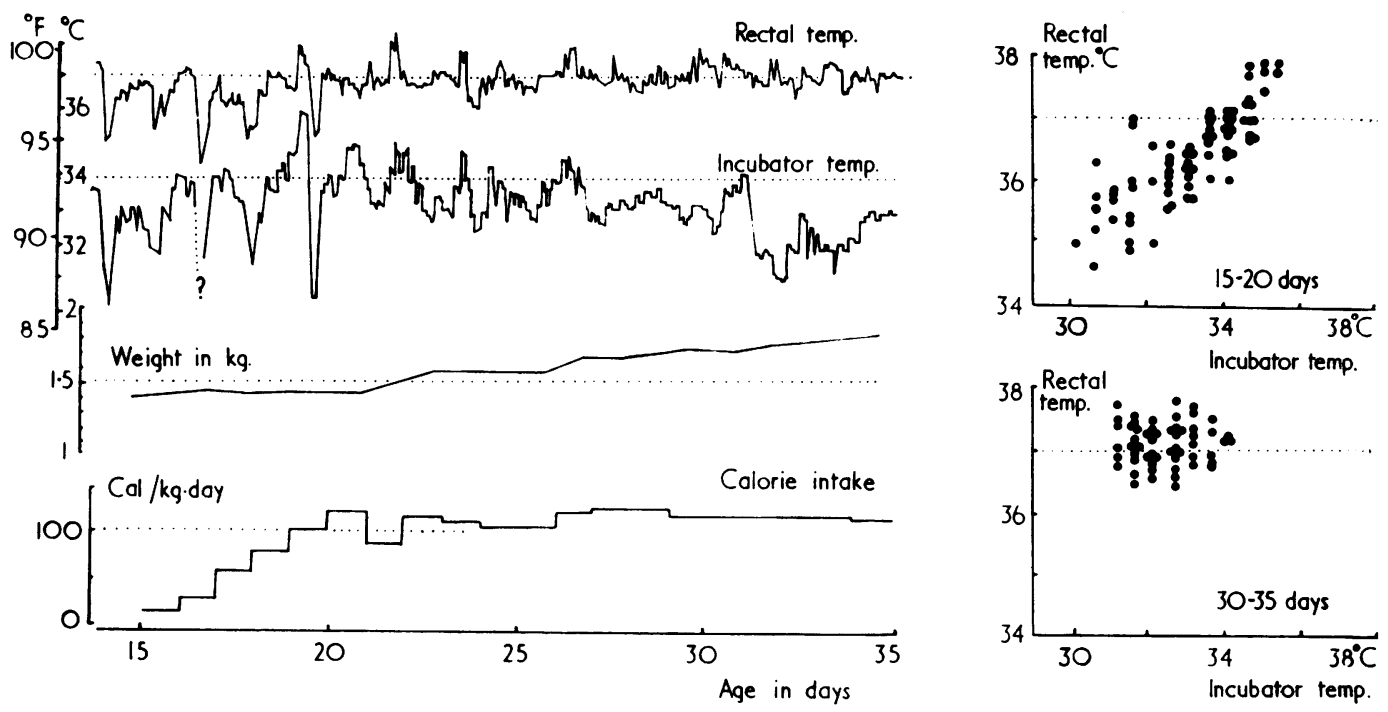

FIG. 3.-The relation between rectal temperature and environmental temperature in Case 1 between the 3rd and 5 th week of life. Mean environmental temperature in the incubator has been calculated from hourly measurements of room temperature and incubator air temperature. Since room temperature was maintained close to $27^{\circ} \mathrm{C}$., the estimate of environmental temperature plotted here is for the most part only about $1{ }^{\circ} \mathrm{C}$. less than the recorded incubator air temperature. Between day 15 and 20, rectal temperature fluctuated with incubator temperature ( $\mathrm{p}<0.01$; top right, inset); by the 5th week of life homeothermy had been re-established, and rectal temperature was largely independent of incubator temperature (bottom right, inset).

and severely acidotic as a result of frank diarrhoea. He was transferred to the Queen Elizabeth Hospital Gastro-enteritis Unit for further treatment; the fluid deficit and acid base balance were corrected by intravenous fluid therapy, and the diarrhoea ceased within 24 hours. At no stage was there any evidence of hypoglycaemia or of neurological abnormality. No pathogenic bacteria were ever isolated. Careful records of room, incubator, and rectal temperature were made hourly for the next 3 weeks (Fig. 3). Analysis revealed that he behaved like a cold-blooded animal for the first few days after transfer, in that his body temperature fluctuated with incubator temperature. By the 4th week of life, when he was on a full calorie intake and had regained his birthweight, this poikilothermic behaviour disappeared, and rectal temperature became once more largely independent of incubator temperature. Heat production was again measured 35 and 49 days after birth. Both basal metabolism and the response to cold stress were now within normal limits (Fig. 2). The child is now over 1 year old, and remains well.

Case 2. Female. Birthweight 1205 g. after 34 weeks' gestation. Normal birthweight at this gestation ( $95 \%$ limits after allowing for sex and parity) is between 1600 and $3100 \mathrm{~g}$. (Thomson, Billewicz, and Hytten, 1968). No obvious physical abnormalities were detected on examination and initial progress was normal. When 13 days old the child was found to be hypothermic, and the next day she became irritable and passed small green rancid stools, from which no pathogens were isolated. Lumbar puncture produced sterile xanthochromic fluid under slight pressure. There was no evidence of hypoglycaemia. Fluids were given intravenously for 24 hours and antibiotics prescribed. The child improved quickly, while stools became normal within a day. On the 17 th day she regurgitated while being fed, collapsed, and became apnoeic. Spontaneous respiration returned after immediate endotracheal intubation, but she remained unresponsive for 36 hours and required intravenous feeding. After this she recovered quickly.

When she was 4 weeks old, the head began to enlarge rapidly, and it became clear that she was developing hydrocephalus, though she remained otherwise well. A low-pressure Spitz-Holter valve was eventually inserted, but this unfortunately became infected and the child died. At necropsy no congenital abnormalities were detected, but gliosis of the aqueduct was present which could well have been haemorrhagic in origin.

Certain features of the child's case history are summarized in Fig. 4. Basal metabolism was normal. The metabolic response to brief cold stress was also normal throughout the first week of life, though the incubator temperature was variable and rather low, and the calorie intake small. The child's metabolic response to cold was, however, reduced at 10 days, and found to be further reduced after a period of hypo- 

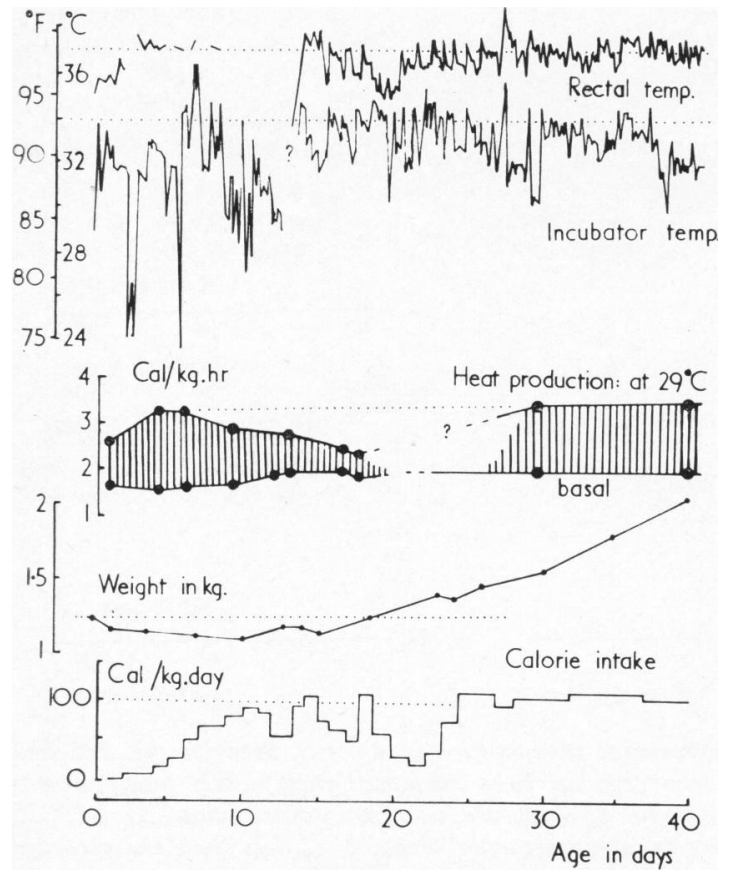

FIG. 4.-This chart summarizes the records of rectal temperature and environmental incubator temperature in Case 2. The records of basal metabolism and of the increase in heat production obtained in response to brief subjection to an environment of $29^{\circ} \mathrm{C}$. are also indicated. The infant's metabolic response to cold stress appeared to become subnormal about the 10th day, but was normal again by the 30th day of life.

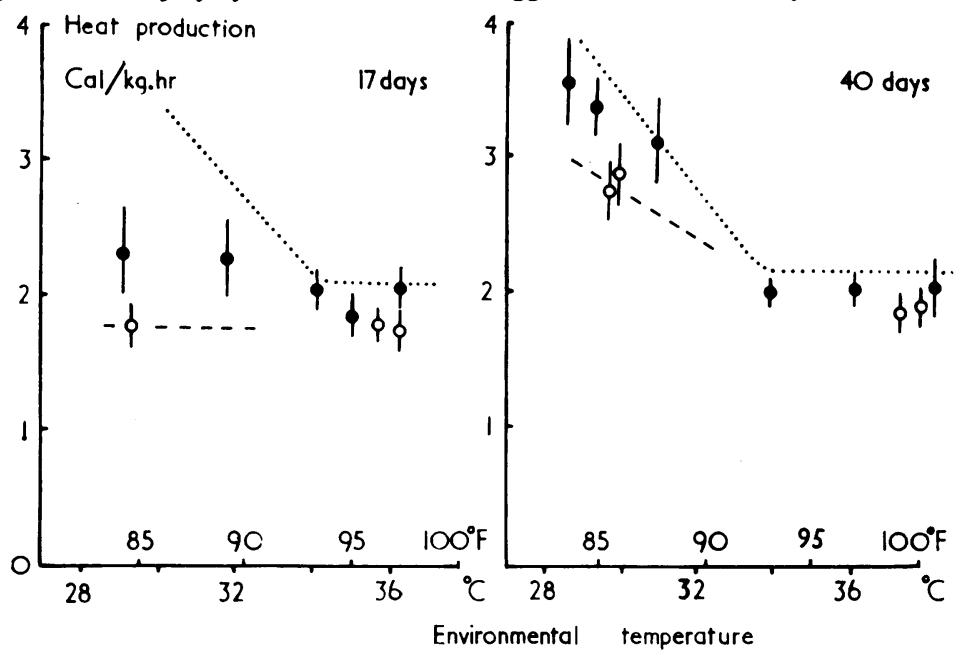

(a) thermia due to low incubator temperatures when 13 days old. At this stage she appeared well, though she was still below her birthweight. Virtually no increase in heat production could be detected when she was 17 days old, though she became active and restless when the environmental temperature was lowered briefly to $29^{\circ} \mathrm{C}$. After sedation with chloral hydrate in order to diminish the heat production due to this vigorous muscular activity, no residual increase in heat production could be detected at $29^{\circ} \mathrm{C}$. (Fig. 5a). Normal changes in heat flow through the hand were, however, present at this time, in response to changes in environmental temperature. No sweating was detected.

At the age of 30 days the metabolic response to cold stress had returned to normal. The child was now on a high calorie intake, gaining weight satisfactorily, and had been in a warmer environment for 10 days. On investigation once more at 40 days the vasomotor, sweating, and metabolic responses to changes in environmental temperature were all normal. Furthermore, a significant increase in heat production in response to cold stress could still be detected when the infant was quiet and apparently asleep after sedation with chloral hydrate (Fig. 5b).

Case 3. Female. Birthweight 1175 g.; one of twins. (The second twin (1245 g.) was distressed and cyanosed from birth and died 7 hours later after a series of apnoeic episodes. Necropsy revealed severe intracranial haemorrhage.) The first twin, in contrast, remained vigorous and relatively well. The period of gestation could not be determined with certainty, but physical and neurological testing (Usher, McLean, and Scott, 1966; Farr et al., 1966; Robinson, 1966) suggested that the baby was between 4 to 6 weeks,

(b)

FIG. 5.-The relation between heat production and environmental temperature in Case 2 before ( $\bullet$ ) and after (O) sedation with chloral hydrate when (a) 17 and (b) 40 days old. Other symbols as in Fig. 2 . A metabolic response to cold stress has returned by the 5th week, and persists when asleep after sedation with chloral (cf. Hey, 1969). 


\section{Temporary Loss of a Metabolic Response to Cold Stress in Infants of Low Birthweight}

premature at the time of delivery. She was nursed in an incubator, with a mean air temperature of $32 \cdot 5^{\circ} \mathrm{C}$. over the first 5 days of life. Room temperature was below $24{ }^{\circ} \mathrm{C}$., and the average rectal temperature was $35{ }^{\circ} \mathrm{C}$. Total food intake in these 5 days was only 130 Cal. The rectal temperature was found to be $33 \cdot 2{ }^{\circ} \mathrm{C}$. when the child was 60 hours old, after the incubator air temperature had fallen to $29^{\circ} \mathrm{C}$. Measurements of heat production $\left(\mathrm{O}_{2}\right.$ consumption) were made as soon as the infant was warm: both basal metabolism and the increase in heat production in a cool environment were normal.

Despite a mean incubator air temperature of $33{ }^{\circ} \mathrm{C}$. over the next $\mathbf{4 8}$ hours, the rectal temperature remained subnormal. Basal metabolic rate was again normal when reassessed on the 5th day, but the metabolic response to cold stress was now seriously reduced. The child, however, still appeared well and vasomotor responses to changes in environmental temperature were normal when tested the following day. Food intake was increased to $120 \mathrm{Cal}$. per day over the next 3 days, and a normal rectal temperature was maintained by nursing the infant partially clothed, with the incubator heat control set at maximum. The child now began to gain weight, and repeat studies on the 9th day of life showed that the ability to increase heat production in response to cold stress had improved. No sweating could be detected.

On the 10th day the child developed diarrhoea which stopped promptly with omission of oral feeds and intravenous fluid therapy. Though no pathogenic bacteria were detected, she was transferred to an isolation unit. When repeat studies were undertaken at 6 weeks, vasomotor, sweating, and metabolic responses to changes in environmental temperature were all normal. The child is now 1 year old: subsequent progress has been uneventful.

These 3 infants did not look ill at the time their ability to increase heat production was first shown to be subnormal, though one subsequently developed severe diarrhoea. The infants were nursed naked in standard commercial incubators. Marked fluctuations in incubator air temperature occurred but an over-all mean air temperature of between 31 and $32.5{ }^{\circ} \mathrm{C}$. was achieved in the first 5 days of life. The babies were on a low daily calorie intake, and were at least $8 \%$ below their birthweight at the time their ability to increase heat production was first shown to be reduced. There was no evidence of hypoxia or hypoglycaemia, and other aspects of temperature control were not disturbed. No neurological abnormalities were detected at this time, though one infant later developed signs of hydrocephalus at a time when temperature regulation had returned to normal.

\section{Discussion}

Most neonatal mammals respond to cold exposure with a substantial increase in heat production. The same response has been demonstrated in the newborn baby (Day, 1943; Brück, 1961) and has recently been quantified in some detail (Hey, 1969). The results summarized in Fig. 1 show that even very small infants are able to double their heat production in response to temporary cold stress, though it cannot be assumed that they would all have been able to maintain this response if nursed in a cool incubator for any length of time (cf. Silverman and Agate, 1964). Increased physical activity in the cold seems to be partially responsible for the increase in heat production observed in naked infants in an environment of $29^{\circ} \mathrm{C}$., but an increase in heat production can also be detected at this temperature in infants who are asleep and apparently motionless.

Recently, it has been shown that in several neonatal animals increased oxidation of triglyceride within brown adipose tissue is responsible for much of the increase in heat production observed during cold stress. This has been most clearly shown in the newborn rabbit (Dawkins and Hull, 1964) and guinea-pig (Brück and Wünnenberg, 1966). When young unfed rabbits are subjected to cold their stores of fat are quickly exhausted, and the normal metabolic response to cold stress is then lost. The fat available in the brown adipose tissue itself seems to be the first to be utilized (Hull and Segall, 1966; Heim and Kellermayer, 1967), but in rabbits with substantial deposits of white adipose tissue these stores are also drawn upon (Hardman, Hey, and Hull, 1969b). Animals that have lost the ability to generate extra heat in cold surroundings can be revived with milk, but not with an equivalent volume of $10 \%$ glucose (Hardman, Hey, and Hull, 1969a).

Small but significant quantities of brown adipose tissue are also present in the human infant. The distribution and appearance of these deposits have been defined by Aherne and Hull (1966), who found that the fat content of the tissue was depleted in a series of infants coming to necropsy with a clinical history of hypothermia or neonatal cold injury. A similar selective histological depletion of brown adipose tissue has been reported by Heim, Kellermayer, and Dani (1968); in contrast it was the white rather than the brown adipose tissue that was depleted in malnourished infants who had been carefully nursed in a warm environment. There are other strands of evidence which also suggest that brown adipose tissue plays a significant part in the increased heat production observed in human infants subjected to cold stress (Dawkins and Scopes, 1965). 
Intracranial haemorrhage can be associated with derangements of temperature control in the human infant (Mestyan, 1962; Mestyán et al., 1962), as can asphyxia at birth (Brück, Brück, and Lemtis, 1960) and congenital defects of the central nervous system (Cross et al., 1966). The normal increase in heat production in a cool environment is abolished by hypoxia (Scopes and Ahmed, 1966) and diminished by sedation (Hey, 1969). There is little evidence that the abnormal metabolic response to cold stress observed in the 3 infants reported here was related to any of these factors: the response was normal in the first few days after birth, and returned to normal after a temporary fall. It could be argued that the derangement of temperature control in Case 2 was due to neurological abnormality or an intracranial haemorrhage, but since only one aspect of temperature regulation appeared to be affected and the loss of response was temporary this seems unlikely. It should be noted that temperature regulation had completely returned to normal in this child when overt signs of raised intracranial pressure first became apparent at the age of 4 to 6 weeks.

The other physiological aspects of temperature regulation did not appear to be disturbed in these 3 babies. They became restless as soon as the environmental temperature was lowered and the normal increase in physical activity occurred. In the 2 infants who were tested, vasomotor responses were found to be normal at the time when the metabolic response to cold stress was absent. None of the infants sweated when first examined, but all 3 later developed normal sweating responses to thermal stimuli. This is what would be expected: infants born after such reduced periods of gestation do not normally sweat significantly until some time after birth (Hey and Katz, 1969a). In Case 1 the loss of response may have been related to the severe attack of gastro-enteritis, but an impaired metabolic response was detected before the infant developed diarrhoea or appeared ill.

Fat usually accounts for less than $3.5 \%$ of the total body mass of babies weighing under $1.5 \mathrm{~kg}$. at birth (Iob and Swanson, 1934), and the fat stores of infants who are underweight for their period of gestation are also thought to be reduced (Gruenwald, 1963). The amount of brown adipose tissue is also limited in premature babies, and Aherne and Hull (1966) in their post-mortem studies frequently found this tissue depleted of fat in infants who were 'small for dates' at birth. The 3 infants reported here, who temporarily lost the ability to increase their heat production normally during cold stress, were fed conservatively and were almost certainly in negative calorie balance throughout the first week of life. Mean air temperature in the incubator was between 31 and $32.5{ }^{\circ} \mathrm{C}$. during this time, and room temperature under $25^{\circ} \mathrm{C}$. These infants could only have maintained a normal body temperature in such an environment if heat production was increased (Hey and Mount, 1967; Hey and Katz, 1969b). A moderate but fairly prolonged cold stress of this magnitude could well have resulted in the utilization of $3 \mathbf{g}$. fat per day by brown adipose tissue. We believe that exhaustion of the readily available fat stores could have been responsible for the observed loss of response to cold stress.

Disturbances of temperature control have frequently been observed in malnourished adults (Keys et al., 1950). Hypothermia is also frequently seen in young children in the tropics suffering from malnutrition (Morley, 1960; Brenton, Brown, and Wharton, 1967), while many of the infants in this country who are found to be hypothermic on admission to hospital when more than 2 weeks old are emaciated and less than $75 \%$ of their expected weight (Arneil and Kerr, 1963). Undernutrition is not generally regarded as an important aetiological factor in babies developing hypothermia in the first 2 weeks of life (Mann, 1967), but in small babies possessing little fat at birth, this factor could well manifest itself rather earlier.

The underlying cause of the disturbance may not be the same in every instance. Newborn rabbits generate extra heat in their brown adipose tissue when placed in cool surroundings, and when the available fat has been utilized they are no longer able to maintain a normal body temperature in the cold. Young pigs in contrast have little or no brown adipose tissue and maintain their body temperature in cold surroundings by shivering: when placed on a restricted diet they develop a low basal metabolism and run an abnormally low body temperature (McCance and Mount, 1960), but they still possess an adequate metabolic response to cold stress.

Any analogy with experimental work on animals must be drawn with care, but the situation that exists in the severely starved human adult is probably similar to that produced in the young pig. On the other hand, it may be that the situation in the human infant is closer to that obtained experimentally in the newborn rabbit, though we have, of course, no direct evidence that the infants we studied were fat depleted, or that their nutritional status was responsible for the observed loss of metabolic response to cold stress. While it is probable that the brown adipose tissue was largely 
depleted of fat, it is less certain to what extent the total fat stores were depleted, and we do not know to what extent the human infant can utilize these reserves for heat production.

Each of the three infants reported here became ill in the neonatal period, but evidence of defective temperature control preceded any sign of overt illness in each case. We suggest there is a prima facie case for believing that the defect in these 3 tiny babies may have resulted from the provision of inadequate warmth at a time when calorie intake was low. Whatever the reason for the temporary loss, there is no doubt that a number of small babies lose the ability to increase their heat production in cold surroundings for a while in the neonatal period.

\section{Summary}

Studies of thermo-regulatory ability have been undertaken at regular intervals throughout the first 6 weeks of life in a series of 28 infants who weighed between 1 and $2 \mathrm{~kg}$. at birth.

Three infants were encountered who had normal responses at birth, but lost much of their ability to increase heat production in a cool environment while in hospital at between 5 and 10 days of age, so that body temperature fell rapidly whenever they were exposed to a cool environment. The infants appeared well at the time this reduced response was first detected. The other factors involved in the normal physiological control of body temperature did not appear to be disturbed.

Low birthweight, together with low incubator temperature in the first few days of life at a time when calorie intake was low, might be implicated in the observed temporary loss of metabolic response to a cold stress of $29^{\circ} \mathrm{C}$. for 20 minutes. 2 of the 3 infants were of low birthweight for their length of gestation; gastro-enteritis may have been an aggravating factor in the third infant.

The defect in temperature regulation was only temporary, and could have resulted from depletion of the fat stores available to the babies' calorigenic brown adipose tissues.

We wish to acknowledge our debt to Professor K. W. Cross for his supervision of this work; to Mr. J. D. Atwell, Dr. R. H. Dobbs, Dr. A. D. M. Jackson, Dr. Patricia Russell, and Dr. Mary Wilmers for permission to report details of the case histories; to Sister Barrett and the staff of the Gastroenteritis Ward at the Queen Elizabeth Hospital; and to Miss E. Bardell and Mrs. J. Freeman of the Neonatal Research Group for their help with the studies reported here.

\section{REFERENCES}

Aherne, W., and Hull, D. (1966). Brown adipose tissue and heat production in the newborn infant. F. Path. Bact., 91, 223.

Arneil, G. C., and Kerr, M. M. (1963). Severe hypothermia in Glasgow infants in winter. Lancet, 2, 756.

Brenton, D. P., Brown, R. E., and Wharton, B. A. (1967). Hypothermia in kwashiorkor. ibid., $1,410$.

Brück, K. (1961). Temperature regulation in the newborn infant. Biol. Neonat. (Basel), 3, 65.

, and Brück, M. (1960). Der energieumsatz hypothermer Frühgeborener. Klin. Wschr., 38, 1125.

- $\longrightarrow$ and Lemtis, H. (1960). Die Temperaturregelung Neugeborener und Frühgeborener nach spontaner und pathologischer Geburt. Geburtsh. u. Frauenheilk., 20, 461.

__, and Wünnenberg, B. (1966). Alterations in thermogenic mechanism during postnatal development: the dependence on environmental temperature conditions. Helgoländer wiss. Meeresunters., 14, 514.

Cross, K. W., Gustavson, J., Hill, J. R., and Robinson, D. C. (1966). Thermoregulation in an anencephalic infant as inferred from its metabolic rate under hypothermic and normal conditions. Clin. Sci., 31, 449.

Dawkins, M. J. R., and Hull, D. (1964). Brown adipose tissue and the response of new-born rabbits to cold. F. Physiol. (Lond.), $172,216$.

- , and Scopes, J. W. (1965). Non-shivering thermogenesis and brown adipose tissue in the human new-born infant. Nature (Lond.), 206, 201.

Day, R. (1943). Respiratory metabolism in infancy and in childhood. XVII. Regulation of body temperature of premature infants. Amer. F. Dis. Child., 65, 376.

Farr, V., Mitchell, R. G., Neligan, G. A., and Parkin, J. M. (1966). The definition of some external characteristics used in the assessment of gestational age in the newborn infant. Develop. Med. Child Neurol., 8, 507.

Gruenwald, P. (1963). Chronic fetal distress and placental insufficiency. Biol. Neonat. (Basel), 5, 215.

Hardman, M. J., Hey, E. N., and Hull, D. (1969a). Energy sources for thermogenesis in the new-born rabbit. F. Physiol. (Lond.), 201, 84P.

- , - and - (1969b). In preparation

Hatfield, H. S., and Wilkins, F. J. (1950). A new heat-flow meter. f. sci. Instrum., $27,1$.

Heim, T., and Kellermayer, M. (1967). The effect of environmental temperature on brown and white adipose tissue in the starving new-born rabbit. Acta physiol. Acad. Sci. hung., 31, 339.

-, 339, and Dani, M. (1968). Thermal conditions and the mobilization of lipids from brown and white adipose tissue in the human neonate. Acta paediat. Acad. Sci. hung., 9, 109.

Hey, E. N. (1969). The relation between environmental temperature and oxygen consumption in the new-born baby. f. Physiol. (Lond.), 200, 589.

- and Katz, G. (1969a). Evaporative water loss in the newborn baby. ibid., 200, 605 .

, and - (1969b). The optimum thermal environment for naked babies. In preparation.

, and Mount, L. E. (1967). Heat losses from babies in incubators. Arch. Dis. Childh., 42, 75.

Hill, J. R., and Rahimtulla, K. A. (1965). Heat balance and the metabolic rate of new-born babies in relation to environmental temperature; and the effect of age and of weight on basal metabolic rate. F. Physiol. (Lond.), 180, 239.

Hull, D., and Segall, M. M. (1966). Distinction of brown from white adipose tissue. Nature (Lond.), 212, 469.

Iob, V., and Swanson, W. W. (1934). Mineral growth of the human fetus. Amer. F. Dis. Child., 47, 302.

Keys, A., Brožek, J., Henschel, A., Mickelsen, O., and Taylor, H. L. (1950). The Biology of Human Starvation. University of Minnesota Press, Minneapolis.

McCance, R. A., and Mount, L. E. (1960). Severe undernutrition in growing and adult animals. 5. Metabolic rate and body temperature in the pig. Brit. F. Nutr., 14, 509.

Mann, T. P. (1967). Hypothermia in the new-born. In Modern Trends in Forensic Medicine, 2, p. 197. Ed. by K. Simpson. Butterworths, London

Mestyán, Gy., Varga, F., Fohl, E., and Heim, T. (1962). Oxygen consumption of hyper- and hypothermic premature infants. Arch. Dis. Childh., 37, 466. 
Mestyan, J. (1962). Neonatal cold injury. Lancet, 1, 690.

Morley, D. C. (1960). Cold injury among children severely ill in the tropics. ibid., $2,1170$.

Robinson, R. J. (1966). Assessment of gestational age by neurological examination. Arch. Dis. Childh., 41, 437.

Scopes, J. W., and Ahmed, I. (1966). Indirect assessment of oxygen requirements in new-born babies by monitoring deep body temperature. ibid., 41, 25.

Silverman, W. A., and Agate, F. J., Jr. (1964). Variation in cold resistance among small newborn infants. Biol. Neonat. (Basel), 6, 113.

Southgate, D. A. T., and Barrett, I. M. (1966). The intake and excretion of calorific constituents of milk by babies. Brit. F. Nutr., 20, 363.
Thomson, A. M., Billewicz, W. Z., and Hytten, F. E. (1968). The assessment of fetal growth. f. Obstet. Gynaec. Brit. Crolth, 75, 903.

Usher, R., McLean, F., and Scott, K. E. (1966). Judgement of fetal age. II. Clinical significance of gestational age and an objective method for its assessment. Pediat. Clin. N. Amer., 13, 835.

Correspondence to The Secretary, Dept. of Physiology, The London Hospital Medical College, Turner St., London E.1. 